\title{
O papel da gestão pedagógica frente ao processo de inclusão dos alunos com necessidades educacionais especiais
}

\author{
The role of the pedagogical management in the process of inclusion of \\ students with special educational needs
}

Josiane Rodrigues Barbosa Vioto Doutoranda do Programa de Pós-Graduação em Educação (PPEDU) UEL - Universidade Estadual de Londrina josivioto@hotmail.com

Celia Regina Vitaliano Dra. Docente do Programa de Pós-Graduação em Educação (PPEDU) UEL - Universidade Estadual de Londrina reginavitaliano@gmail.com

\begin{abstract}
Resumo: O objetivo deste artigo é contribuir para a reflexão sobre o papel do gestor pedagógico frente ao processo de construção de escolas inclusivas. A metodologia utilizada para alcançar tal objetivo foi o estudo bibliográfico. Para tanto, foram realizadas consultas a artigos de periódicos, livros, dissertações e teses que abordam o papel do gestor pedagógico frente à inclusão de alunos com necessidades educacionais especiais (NEE). Os resultados evidenciaram que, frente à inclusão de alunos com NEE, cabe às escolas de ensino regular desenvolver uma nova cultura escolar, pautada nos direitos humanos, em especial o direito de todos os alunos se beneficiarem de um ensino de qualidade. Neste processo de mudança, o papel do gestor pedagógico será promover a transformação nas formas organizacionais da escola, eliminando as barreiras que possam impedir o sucesso na escolarização dos referidos alunos, além de envolver neste processo toda a comunidade escolar, visando à valorização e utilização de práticas inclusivas, por meio de capacitação e reflexões de modo compartilhado.
\end{abstract}

Palavras-chave: Coordenador pedagógico. Política nacional de alfabetização. Processo alfabetizador.

Abstract: The purpose of this research rests on the role of the pedagogical coordinator in educational policy in the context of literacy. The objective is to analyze, in analogy to the Penélope canvas metaphor, how the aforementioned policy prescribes the role of the pedagogical coordinator, in the temporal cut-off 2009-2019. The theoretical model used is based on dialectical historical materialism. The methodological approach is qualitative, with bibliographical and documentary analysis. It can be seen that the above policy reproduces throughout the Programs the role of the pedagogical coordinator linked to bureaucratic action, either in the implementation or by assigning responsibility for the systems designed to manage the literacy process, which favors inadequate working conditions, inconsistency and lack of objectivity in the role of the pedagogical coordinator, that is, in the exploitation of this class, which constitutes, within the framework of the National Literacy Policy, a Penelope's canvas.

Keywords: Inclusive education; Inclusive school; Pedagogical management; Special Educational Needs 


\section{Introdução}

A legislação vigente no século XXI representa, sem dúvida, uma evolução nas políticas dirigidas às pessoas com necessidades educacionais especiais (NEE). Pensar no aluno como a origem de um problema, exigindo-se dele que se adéque à escola, é uma leitura inconcebível nos dias atuais (MENDES, 2006). Espera-se da escola atual um ambiente acolhedor e prazeroso, que proporcione a todos os alunos o acesso, a permanência, bem como o aprendizado com sucesso e qualidade, independentemente de suas características físicas, cognitivas, sociais ou culturais (RODRIGUES, 2008; CARVALHO, 2004).

Embora a realidade esteja longe de concretizar os ideais de uma educação para todos, é de fundamental importância a efetivação das políticas existentes para que mecanismos legais possam garantir o direito de todas as crianças conviverem e aprenderem juntas em espaços regulares de ensino (GARCIA, 2007). Nessa perspectiva, o grande desafio é organizar as escolas de forma que possam contribuir com o aprendizado de todos os alunos, em especial aos que apresentam NEE.

São inúmeros os pesquisadores que, nas últimas décadas, têm dedicado os seus estudos em relação ao conceito e pressupostos da educação inclusiva. Dentre outros, destacam-se os trabalhos realizados por Mendes (2006), Glat (2007), Carvalho (2004), Beyer (2006). Ao levar em consideração os estudos realizados pelos referidos autores, caracterizamos a Educação Inclusiva como um novo princípio educacional, que tem como base, a heterogeneidade nas classes regulares de ensino.

Carvalho (2004, p. 36) postula que a educação inclusiva pressupõe um movimento contra qualquer tipo de exclusão que venha a ocorrer dentro dos espaços educacionais do ensino regular, na medida em que se assenta “[...] na defesa dos direitos humanos de acesso, ingresso e permanência com sucesso em escolas de boa qualidade, o que, necessariamente, implica previsão e provisão de recursos de toda ordem”. Dessa forma, defende que deve possibilitar a todas as pessoas oportunidades educacionais adequadas, respeitando, durante todo o processo de aprendizagem, a individualidade, assim como as limitações inerentes de cada ser.

Constata-se, portanto, que o conceito de educação inclusiva pressupõe respostas educativas das escolas a todos os alunos que ali se encontram. Seja qual for a modalidade de ensino, é preciso ter, como prioridade, a efetivação do processo ensino-aprendizagem com base na diversidade e não mais na homogeneização (MENDES, 2006; RODRIGUES, 2008; VITALIANO, 2002).

Tendo em vista essa meta, Beyer (2006, p. 76) acrescenta que um dos principais desafios, considerando a proposta da educação inclusiva, é construir e pôr em prática no ambiente escolar 
uma pedagogia que consiga ser comum ou válida para todos os alunos da classe escolar, porém "[...] capaz de atender os alunos cujas situações pessoais e características de aprendizagem requeiram uma pedagogia diferenciada", possibilitando a comunidade escolar, uma conscientização crescente dos direitos de cada um.

É nesse contexto que o papel do gestor escolar se destaca, por ser ele quem contribui com a estrutura organizacional das escolas, visando transformações. À vista disso, para que se almeje uma escola regular que atenda às NEE dos alunos, é necessário que se tenha um gestor escolar que esteja comprometido com a proposta da educação inclusiva, disposto a mobilizar toda a comunidade escolar no que se refere à questão em foco.

Com base em tais análises, este artigo tem como objetivo descrever as contribuições da gestão escolar pedagógica recomendadas pela produção acadêmica para a inclusão escolar, bem como as barreiras que impossibilitam o desenvolvimento do trabalho do gestor pedagógico no referido contexto.

\section{Método}

Este estudo se baseia em pesquisa bibliográfica, realizado por meio de um levantamento junto às revistas brasileiras que publicam artigos na área da Educação, especialmente da área de Educação Especial, consulta a livros disponíveis na biblioteca da Universidade Estadual de Londrina e no banco de dissertações e teses da CAPES, publicados entre os anos de 2005 a 2015.

Iniciou-se a coleta dos dados mediante uma busca sistematizada em sites de revistas na área da Educação, especialmente na área de Educação Especial, pesquisa de livros no acervo da Biblioteca da Universidade Estadual de Londrina, de levantamento no banco de dissertações e teses da CAPES, com o objetivo de se identificar trabalhos acadêmicos que apresentassem as contribuições da gestão escolar no processo da educação inclusiva. $\mathrm{Na}$ sequência, realizou-se a leitura dos textos ou artigos completos para identificar se traziam, em suas discussões, sugestões com relação à contribuição dos gestores escolares no processo de inclusão dos alunos com NEE. Considerando que a gestão escolar engloba aspectos relacionados à organização administrativa e pedagógica da escola, o critério utilizado para seleção dos trabalhos a serem analisados foi de que esses apresentassem as especificidades em relação ao trabalho da gestão "pedagógica" frente à inclusão de alunos com NEE. 
Ao todo, foram encontradas 28 obras referentes ao objetivo em questão, relacionadas ao papel da gestão pedagógica no processo de educação inclusiva. Assim, o material coletado foi organizado em quatro categorias amplas, seguindo as orientações de Bardin (1977) que são: o papel do gestor pedagógico na organização da escola inclusiva, o papel do gestor pedagógico em relação às práticas pedagógicas inclusivas, o papel da gestão pedagógica concernente à gestão participativa e ao processo educacional inclusivo e o papel da gestão pedagógica e as barreias que impedem a organização da escola inclusiva.

A seguir, apresentar-se-ão as categorias que orientaram a análise dos resultados.

\section{0 papel do gestor pedagógico na organização da escola inclusiva}

Encontram-se, em oito dos textos analisados, referências à conscientização do gestor pedagógico em relação à organização de escolas educacionais inclusivas: Sousa (2007); Michels (2006); Lima (2005); Valim (2013); Freitas (2014); Luziete (2015); Cavalcanti (2014); Patuzzo (2014).

Sousa (2007, p. 51) pondera que o gestor pedagógico "ao estabelecer uma demanda de trabalho centrada nas idéias de uma Educação Inclusiva, colabora com a vivência da diversidade priorizando as singularidades das pessoas e as aprendizagens ocasionadas dos encontros com a multiplicidade", contemplando ações que visam oportunizar espaços de reflexões acerca de um processo decisório participativo, priorizando uma ação planejada eficaz ao processo de Educação Inclusiva.

Sob essa mesma perspectiva, Michels (2006) acredita que o gestor pedagógico deve ser o primeiro a se conscientizar do seu papel na organização da escola de modo que se torne inclusiva. Só assim será possível promover mudanças educacionais de forma a transformar as escolas, que historicamente se caracterizaram, como espaços educacionais destinados ao atendimento de alunos em classes regulares homogêneas em escolas inclusivas em que a heterogeneidade seja percebida como princípio básico para elaboração de todas as propostas pedagógicas.

Semelhante às análises dos autores supracitados, Valim (2013, p. 35) defende que: “[...] a gestão escolar deve promover a inclusão escolar em seu sentido amplo, o que significa não deixar nenhum aluno fora da escola e ir além: a gestão escolar deve mudar o seu posicionamento em relação aos princípios da educação [...]”, considerando, para tanto, uma transformação no modo de pensar e agir no referido contexto escolar. 
Luziete (2015, p. 127), assim como Freitas (2014), Cavalcanti (2014) e Patuzzo (2014), ao tecer considerações em relação ao papel da gestão pedagógica no desenvolvimento da educação inclusiva, considera que ao assumir a posição de gestor, o Pedagogo deve reorganizar seus conceitos acerca de deficiência, ensino e aprendizagem. Essa conscientização e mudança são imprescindíveis, até mesmo porque será ele um dos principais responsáveis pela: “[...] sensibilização da comunidade escolar para o reconhecimento da diversidade humana e da capacidade que todos têm de aprender". Nesse sentido, deverá focar sua organização para a inclusão, através da elaboração coletiva de uma proposta pedagógica que retrate a realidade de seus alunos, bem como as suas reais necessidades. A partir dessas atitudes é que será possível uma mudança atitudinal, uma reorganização curricular com base em uma formação de rede de apoio que contemple a formação docente, a participação da família, a acessibilidade e a organização de atendimentos educacionais especializados.

Alerta Lima (2005, p. 100) que "assumir o compromisso de organizar uma escola inclusiva está longe de ser uma tarefa fácil, cômoda ou simples", até mesmo porque esta transformação coloca em choque os antigos valores estabelecidos em meio a este contexto, assim como desnuda as falhas e expõe as escolas a suas limitações. Entretanto, de acordo com a mesma autora, é necessário considerarmos que, somente por meio das transformações decorrentes nos sistemas organizacionais educacionais, a escola poderá criar novos valores e, consequentemente, desenvolver uma nova cultura escolar. O ponto de partida, portanto, consiste na conscientização de todos os profissionais envolvidos nesse processo, em especial a gestão pedagógica.

\section{$2 \mathrm{O}$ papel do gestor pedagógico em relação às práticas pedagógicas inclusivas}

Identificam-se sete autores que destacam como função do trabalho do gestor pedagógico o desenvolvimento de estratégias instrucionais em relação ao processo educacional inclusivo: Gil (2005); Penaforte (2009); Tezani (2010); Valim (2013); Cavalcanti (2014); Kailer e Papi (2014).

Para Penaforte (2009), o desafio do gestor pedagógico é desenvolver estratégias instrucionais que possibilitem respostas às variadas necessidades e situações de aprendizagem. Para tanto, cabe a ele, além de diagnosticar as possíveis necessidades dos professores perante o processo de inclusão de alunos com NEE, encontrar alternativas viáveis que possam contribuir não só com a prática inclusiva do professor, mas com o aprendizado dos alunos, seja qual for sua necessidade. 
Na mesma perspectiva, Gil (2005, p. 5) indica que o gestor pedagógico pode contribuir com a prática dos professores, ajudando-os a desenvolver "[...] habilidades e estratégias educativas adequadas às necessidades de cada aluno, respeitando a potencialidade e dando respostas adequadas aos desafios apresentados pelos alunos, a partir de análises reflexivas”.

Tezani (2010), ao realizar estudos na área em destaque, chegou às considerações de que as mudanças no contexto das salas de aula, bem como do trabalho a ser realizado pelos professores em relação ao processo de inclusão de alunos com NEE poderão ser mais eficazes se houver, durante o processo, a participação ou mesmo a contribuição dos gestores pedagógicos. A autora cita exemplos de ações que são importantes, dentre as quais destacam-se: auxiliar os professores na identificação das NEE apresentadas pelos alunos; elaboração de currículos dinâmicos, flexíveis e adaptáveis que permitam ajuste ao fazer pedagógico de acordo com as necessidades dos alunos; desenvolver adaptações físicas e sociais, estabelecendo redes de apoio que possibilitem um trabalho compartilhado entre profissionais do ensino regular, profissionais especialistas e comunidade escolar; auxiliar os professores no desenvolvimento de metodologias de ensino diferenciadas; possibilitar aos professores momentos de reflexão em relação aos processos educacionais inclusivos.

Corroborando com as ideias das autoras supracitadas, Valim (2013, p. 34) aborda que um dos grandes desafios da gestão “[...] é fazer a integração entre os alunos e contribuir com a formação dos professores em exercício para que os alunos possam, através de suas habilidades, desenvolverem atividades a partir das diferenças". Mesmo porque, para que o processo de aprendizagem dos alunos com NEE ocorra de forma progressiva e satisfatória, é necessário que gestores, professores e demais profissionais envolvidos no processo levem em consideração as características peculiares de cada aluno, só assim será possível desenvolver estratégias que auxiliem na promoção das habilidades individuais.

Nessa mesma linha de raciocínio, Cavalcanti (2014), Kailer e Papi (2014) defendem que a esse profissional cabe intervir na reflexão do grupo de professores, auxiliando-os no planejamento da prática que desenvolvem, motivando-os a buscar novas possibilidades ou alternativas para o trabalho pedagógico que desenvolvem.

De um modo geral, os autores reforçam a ideia de que, para se promover a inclusão, é necessário que a gestão pedagógica desenvolva um trabalho pautado na participação ativa junto aos docentes, contribuindo não apenas com orientações didáticas, mas com a organização dos planejamentos de ensino a serem realizados, considerando o atendimento aos alunos com NEE. 
3 O papel da gestão pedagógica no que concerne à gestão participativa e ao processo educacional inclusivo

Essa foi a categoria mais citada dentre todos os trabalhos analisados. Quatorze autores destacam em suas análises a gestão participativa como uma das formas mais viáveis de inserir a comunidade escolar no processo educacional inclusivo: Tezani (2010); Lück (2004); Azevedo e Cunha (2008); Sousa (2007); Dutra e Griboks (2005); Santos (2011); Cavalcanti (2014); Kailer e Papi (2014); Pinheiro (2015); Freitas (2014); Luziete (2015).

Para Tezani (2010), a criação de um ambiente escolar adequado à aprendizagem exige, por parte da gestão pedagógica, um trabalho participativo, no qual planejamentos e implementação de estratégias sejam estruturados e desenvolvidos com a participação de todos os envolvidos no processo, com a necessidade da construção de uma comunidade inclusiva que englobe o planejamento e o desenvolvimento curricular; a preparação da comunidade escolar, a fim de desenvolver um programa de equipe em progresso contínuo, com possibilidades de desenvolvimento de trabalho cooperativo e socialização de saberes.

Assim como Tezani (2010), Azevedo e Cunha (2008, p. 67) especificam como trabalho da gestão pedagógica: “articular o processo da educação inclusiva, oportunizar a integração entre todos os envolvidos no processo educativo, estabelecer relações e interrelações entre toda comunidade escolar".

Para os autores Azevedo e Cunha (2008), Lück (2004) e Tezani (2010), as dificuldades relacionadas ao processo de ensino e aprendizagem dos alunos com NEE devem ser analisadas pelo próprio grupo que compõe a comunidade escolar, e não só pela figura exclusiva do professor ou do gestor pedagógico. Logo, todos os profissionais que compõem a comunidade escolar devem se "comunicar" de maneira que a proposta, a fala e a ação sejam coerentes com as práticas pedagógicas inclusivas.

Conforme Sousa (2007, p. 5), é “[...] através da reflexão das ações pedagógicas dos professores e demais profissionais, que os cenários são reconstruídos e ressignificados dentro do conjunto de procedimentos e atitudes que o processo educacional abrange”. Logo é preciso que o gestor pedagógico compreenda o seu papel de articulador e promotor de um espaço que oportunize a participação de todos os envolvidos no processo ensino/aprendizagem.

Dutra e Griboks (2005, p. 3) também destacam o trabalho participativo, orientado pela gestão pedagógica como um trabalho fundamental no processo educacional inclusivo, visto que 
todos os envolvidos no processo de ensino/aprendizagem: "[...] na implementação e acompanhamento do projeto educacional com vistas à construção de escolas inclusivas, abertas à participação e aprendizagem de todos os alunos".

Pinheiro (2015, p. 23), ao analisar as funções da gestão pedagógica no que tange à organização da escola inclusiva, afirma que: “[...] a função dele é pedagógica, de ser um mediador em colaboração com os professores para traçar teorias e práticas de como melhorar o ensino naquela instituição, inclusive no que se refere à inclusão de crianças com necessidades especiais". A proximidade no trabalho com os professores não permitirá que a hierarquia seja um obstáculo no objetivo maior que é melhorar a qualidade no ensino.

Freitas (2014, p. 134) “[...] ressalta a importância da liderança do gestor escolar a ser trabalhada de forma mais compartilhada e que venha a contribuir com um clima participativo e favorecendo a inclusão”. Entre outras palavras, na medida em que o gestor trabalha como um agente de mobilização, ele proporciona o engajamento de todos os profissionais da escola para participar e se envolver nos processos inclusivos.

Sua proposta pedagógica conclama docentes e gestores à união para o desenvolvimento de um trabalho pedagógico inclusivo, que corresponda às necessidades educacionais especiais de todos os estudantes, independente de suas necessidades de aprendizagem.

Luziete (2015) e Cavalcanti (2014) analisam que a gestão compartilhada pode contribuir para o desenvolvimento de uma política que pode favorecer o direito de todos à educação. Para as autoras mencionadas, a gestão democrática ou compartilhada podem ser entendidas como um dos pilares para a implementação de uma política educacional inclusiva que tem, como objetivo, efetivar a educação como direito de todos. Para tanto, a flexibilidade no trabalho da gestão pedagógica é uma das condições indispensáveis, tendo em vista que deverá considerar a diversidade de opiniões.

Com relação à mesma questão, Kailer e Papi (2014, p. 9) ressaltam que, tendo em vista o processo de inclusão, o papel do pedagogo, enquanto um dos gestores da escola, é o de "[...] favorecer e coordenar o desenvolvimento de práticas pedagógicas que interfiram tanto na docência, quanto na promoção de medidas de acessibilidade, facilitando a participação democrática e o desenvolvimento de uma educação de qualidade".

Alerta Santos (2011, p. 28), todavia, que “a construção de uma gestão democrática que vise à inclusão escolar constitui-se, ainda, num grande desafio que requer a colaboração de todos para ser superado, inclusive das políticas públicas educacionais”. 


\section{O papel da gestão pedagógica e as barreiras que impedem a organização da escola inclusiva}

Dentre os trabalhos analisados, identificam-se seis autoras que, ao caracterizarem o papel da gestão pedagógica, destacam algumas barreiras que, na atualidade, impedem o trabalho do referido profissional em relação à organização e ao desenvolvimento de uma escola inclusiva: Tezani (2010); Santos (2011); Penaforte (2012); Pinheiro (2015); Luziete (2015); Monteblanco (2015).

De acordo com Tezani (2010), não há dúvidas de que a gestão pedagógica é uma das responsáveis pela construção da escola inclusiva, porém é fato que essa educação, no atual contexto educacional, só se efetivará se houver investimento em capital humano por parte dos sistemas educacionais de ensino.

Penaforte (2012, p. 26), ao desenvolver estudos relacionados ao papel da gestão pedagógica na organização da escola inclusiva, considera que: "é necessário engajamento dos poderes públicos para garantirem condições de acompanhamento profissional, técnico e especializado, enquanto condição de permanência, de evolução e de bem-estar das crianças ditas diferentes”. Dessa forma, para que a gestão pedagógica possa contribuir com o desenvolvimento da educação inclusiva, torna-se essencial o apoio de nosso sistema governamental.

Tezani (2010, p. 299), em análise semelhante, destaca que: “os servidores municipais padecem com a precarização das suas remunerações", logo se sentem desmotivados a desenvolverem ações que inviabilizem o processo educacional inclusivo. Diante dessa constatação, a autora acrescenta que: "[...] se faz necessário recuperá-las de maneira gradual e responsiva".

Outro aspecto que chamou a atenção de Tezani (2010, p. 299), no desenvolvimento de seu estudo, foi o fato de os professores que atuam no atual contexto escolar não disponibilizarem de tempo para que possam desenvolver planejamentos, levando em consideração a participação de todos os envolvidos no processo educacional inclusivo. Diante dessa limitação, a autora sugere que: “[...] acrescente-se dentro da jornada de trabalho dos professores horas destinadas à preparação das aulas, correção de atividades, aperfeiçoamento docente".

Luziete (2015, p. 128), por sua vez, acredita que ainda há muitas barreiras que dificultam a gestão pedagógica para o desenvolvimento de um trabalho pautado nas propostas educacionais inclusivas. Dentre elas, a autora destaca a falta de tempo para estudos para aprofundar os 
conhecimentos acerca das deficiências e de como lidar com elas no contexto escolar. A autora reconhece que esse é um desafio constante na escola: "[...] ir se preparando e ao mesmo tempo atendendo os alunos nela matriculados".

Ao referir-se às barreiras que impossibilitam o trabalho da gestão pedagógica na organização da escola inclusiva, Monteblanco (2015, p. 71) destaca a falta de contato dos gestores com os profissionais da Educação Especial. Para autora, “os serviços de Educação Especial não estão vinculados com as escolas em si [...]”, falta diálogo entre especialistas da área e a gestão pedagógica. Para a autora, esse fato ocorre devido à falta de tempo, tanto por parte da gestão pedagógica como dos especialistas da área da Educação Especial, para o desenvolvimento de planejamentos em conjunto, considerando as necessidades de aprendizagem dos alunos com NEE.

Pinheiro (2015, p. 22), assim como Santos (2011), ao analisarem as barreiras que impedem o trabalho da gestão pedagógica, considerando as propostas educacionais inclusivas, destacam que o papel do coordenador pedagógico nas escolas regulares de ensino é bastante distorcido por grande parte das pessoas que compõe a comunidade escolar, uma vez que, “[...] ao realizar atividades de outro profissional, as atividades de competência do seu cargo deixam de ser realizadas, o que com certeza trará prejuízos para todos”. Desse modo, situações imediatistas, que fogem da especificidade do trabalho da gestão pedagógica, poderão comprometer as práticas colaborativas a serem desenvolvidas com os professores no contexto escolar.

Pelo exposto, nota-se que a falta de conhecimentos (ou o não cumprimento) da comunidade escolar em relação às especificidades do trabalho da gestão pedagógica é um dos empecilhos que interfere na organização da escola inclusiva. Ao analisar as pesquisas supracitadas, é possível se observar que o papel da gestão pedagógica vai além de um atendimento imediatista, haja vista que é responsabilidade do gestor organizar reuniões pedagógicas com o objetivo de auxiliar o professor no desenvolvimento de planejamentos, considerando práticas inclusivas, fornecendo a este profissional o suporte técnico e científico necessário a fim de atingir os objetivos pedagógicos; realizar as adaptações de grande porte e promover a acessibilidade no contexto escolar.

\section{Considerações finais}


Com base nos estudos dos autores pesquisados em relação ao processo educacional inclusivo e às contribuições da gestão pedagógica para promover sua efetivação e seu desenvolvimento, considera-se que cabe ao gestor identificar e se mobilizar para prover os recursos materiais e humanos necessários a uma empreitada de sucesso no que se refere ao processo de aprendizagem dos alunos com NEE. Espera-se que por meio de cobrança junto aos sistemas de ensino, obtenham-se os investimentos necessários para o atendimento das necessidades emergentes, promovendo capacitação e discussões que auxiliam os professores no desenvolvimento de metodologias e no de estratégias de ensino diferenciados ao favorecer o processo educacional inclusivo. Também se espera a possibilidade, no contexto escolar, de momentos de reflexão com relação às práticas pedagógicas inclusivas, de forma que todos os envolvidos possam atuar na definição dos objetivos, do planejamento, bem como na elaboração de propostas e planos de ação que possibilitem a quebra das barreiras, a qual esteja impedindo o desenvolvimento da aprendizagem dos alunos com NEE.

Neste contexto, é possível tecer algumas ponderações a respeito das barreiras que impossibilitam o desenvolvimento da organização da escola inclusiva, particularmente em relação ao trabalho da gestão pedagógica no que se refere ao processo em destaque. Os resultados da pesquisa possibilitam afirmar de que não basta seguir a legislação vigente se a própria escola e a comunidade local não estão conscientes do papel da gestão pedagógica e de suas especificidades no seu trabalho, assim como não investem na organização da escola inclusiva. É importante que todos se conscientizem que a equipe da gestão pedagógica da escola tem responsabilidades que lhe são próprias. À vista disso, faz-se necessária que seja devidamente especificada e fortalecida a atuação desses profissionais, haja vista que a sensibilização dos professores e demais profissionais da escola para o desenvolvimento do processo de educação inclusiva dependerá da conscientização e de ações da gestão pedagógica frente ao referido processo.

\section{Referências}

AZEVEDO, M. A. R.; CUNHA, G. R. Gestão escolar e educação inclusiva: uma parceria necessária e emergente na escola. Revista Educação: teoria e prática, Rio Claro, v. 18, n. 31, p. 5372, jul./dez. 2008. Disponível em:

$<$ http://www.periodicos.rc.biblioteca.unesp.br/index.php/educacao/article/viewFile/2204/192 9>. Acesso em: 15 jul. 2011.

BARDIN, L. Análise de conteúdo. Lisboa: Edições 70, 1977.

BEYER, H. O. Da integração escolar à educação inclusiva: implicações pedagógicas. In: BAPTISTA, C. R. (org.). Inclusão e escolarização: múltiplas perspectivas. Porto Alegre: Mediação, 2006. p. 73-81. 
CARVALHO, R. E. Educaşão inclusiva: com os pingos nos “is". Porto Alegre: Mediação, 2004.

CAVALCANTI, A. V. O papel do gestor escolar no processo de inclusão. Colloquium Humanarum, Presidente Prudente, v. 11, n. esp., p. 1014-1021, jul./dez. 2014. DOI:

10.5747/ch.2014.v11.nesp.000632.

DUTRA, C. R.; GRIBOSKI, C. M. Gestão para a inclusão. Revista Educação Especial, Santa Maria, v. 2, n. 1, 2005. Disponível em: < http://coralx.ufsm.br/revce/ceesp/2005/02/a1.htm >. Acesso em: 2 jul. 2010.

FREITAS, F. P. M. Gestão e inclusão escolar: a formação do gestor escolar no programa "Educação inclusiva: direito a diversidade" (2003-2013). 2014. 169 f. Dissertação (Mestrado em Educação) Unicentro, Guarapuava, 2014.

GARCIA, R. M. C. O conceito de flexibilidade curricular nas políticas publicas de inclusão educacional. In: JESUS, D. M. (org.). Inclusão, práticas pedagógicas e trajetórias de pesquisa. Porto Alegre: Mediação, 2007. p. 11-20.

GIL, M. Educação inclusiva: o que o professor tem a ver com isso? São Paulo: Realização USP, 2005. Disponível em: < http://saci.org.br/pub/livro educ incl/redesaci educ incl.html>. Acesso em: 18 dez. 2018.

GLAT, R. (org.). Educação inclusiva: cultura e cotidiano escolar. Rio de Janeiro: 7 Letras, 2007.

KAILER, P. G. L.; PAPI, S. O. G. O papel do pedagogo em relação à inclusão escolar. In: ANPED SUL, 10., Florianópolis. Anais [...]. Florianópolis, 2014.

LIMA, L. Apertem os cintos, a direção (as) sumiu! Os desafios da gestão nas escolas inclusivas. In: FREITAS, S. N.; RODRIGUES, D.; KREBS, R. Educação inclusiva e necessidades educacionais especiais. Santa Maria: Ed. UFSM, 2005. p. 85-111.

LÜCK, H. A dimensão participativa da gestão escolar. Gestão em Rede, Curitiba, v. 57, p. 1- 6, 2004.

LUZIETE, N. F. Educação escolar inclusiva: desafios e possibilidades de uma escola aberta para todos. 2015, 151 f. Dissertação (Mestrado Profissional em Gestão e Avaliação da Educação Pública) - Faculdade de Educação, Universidade Federal de Juiz de Fora, MG, 2015.

MENDES, E. G. A radicalização do debate sobre inclusão escolar no Brasil. Revista Brasileira Educação, Rio de Janeiro, v. 11, n. 33, p. 387-405, 2006.

MICHELS, M. H. Gestão, formação docente e inclusão: eixos da reforma educacional brasileira que atribuem contornos à organização escolar. Revista Brasileira Educação, Rio de Janeiro, v. 11, n. 33, p. 406-423, set./dez. 2006. Disponível em:

< http://www.scielo.br/pdf/rbedu/v11n33/a03v1133.pdf > . Acesso em: 5 ago. 2010.

MONTEBLANCO, V. M. A escola comum/ educação especial: a relação da gestão com as práticas inclusivas. 2015. 94 f. Dissertação (Mestrado em Educação) - Universidade Federal de Santa Maria, Santa Maria, 2015. 
PATUZZO, K. G. O pedagogo no contexto da inclusão escolar: possibilidades de ação na escola comum. 2014. 193 f. Dissertação (Mestrado em Educação) - Universidade Federal do Espirito Santo, Vitória, 2014.

PENAFORTE, S. A gestão para a inclusão: uma pesquisa-ação colaborativa no meio escolar. 2009. Tese (Doutorado em Educação) - Universidade Federal do Ceará, Fortaleza, 2009.

PENAFORTE, S. Gestão e organização da escola para a inclusão: o acompanhamento como fator de mudanças. In: REUNIÃO DA ANPED, 35. 2012, Porto de Galinhas. Anais [...]. Porto de Galinhas, 2012. Disponível em:

http://35reuniao.anped.org.br/images/stories/trabalhos/GT15\%20Trabalhos/GT15-

2057_int.pdf. Acesso em: 10 ago. 2016.

PINHEIRO, C. R. A gestão educacional inclusiva na escola. 2015. 58 f. Dissertação (Mestrado em Teologia) - Faculdades EST, Escola Superior em Teologia, São Leopoldo, 2015.

RODRIGUES, D. Desenvolver a educação inclusiva: dimensões do desenvolvimento profissional. Inclusão: revista da educação especial, Brasília, v. 4, n. 2, jul/out. 2008.

SANTOS, R. R. S. Gestão escolar para uma escola inclusiva: conquistas e desafios. 2011. 90 f.

Dissertação (Mestrado em Educação) - Universidade do Oeste Paulista - UNOESTE, Presidente Prudente, 2011.

SOUSA, L. P. F. Orquestrar a gestão escolar para respostas educativas na diversidade. 2007, 113 f.

Dissertação (Mestrado em Educação) - Universidade do Estado do Rio de Janeiro, Faculdade de Educação, Rio de Janeiro, 2007.

TEZANI, T. C. R. Gestão escolar: a prática pedagógica administrativa na política de educação inclusiva. Revista Educação, Santa Maria, v. 35, n. 2, p. 287-302, maio/ago. 2010.

VALIM, R. A. A. O papel do gestor escolar para uma escola inclusiva do ensino fundamental I. 2013. 103 f. Dissertação (Mestrado em Educação) - UNICID - Universidade Cidade de São Paulo, São Paulo, 2013.

VITALIANO, C. R. Concepções de professores universitários da área de educação e do ensino regular sobre o processo de integração de alunos especiais e a formação de professores. 2002. 308 f. Tese (Doutorado em Educação) - UNESP - Universidade Estadual Paulista, Marília, 2002.

Recebido em: 18 abr. 2019 / Aprovado em: 16 out. 2019

\section{$\underline{\text { Cite como }}$}

VIOTO, Josiane Rodrigues Barbosa, VITALIANO, Celia Regina. O papel da gestão pedagógica frente ao processo de inclusão dos alunos com necessidades educacionais especiais. Dialogia, São Paulo, n. 33, p. 47-59, set./dez. 2019. Disponível em:

https://doi.org/10.5585/Dialogia.n33.13671. 